\title{
PATH FOLLOWING CONTROL FOR UNDERACTUATED AUV BASED ON FEEDBACK GAIN BACKSTEPPING
}

\author{
Xiao Liang, Yuan You, Linfang Su, Wei Li, Jundong Zhang
}

Original scientific paper In order to achieve path following control for the underactuated AUV in the horizontal plane, we propose that the tracking error equations are established based on virtual target and a novel backstepping method is designed based on Lyapunov stability theorem and feedback gain technique. The nonlinear terms in the error dynamic model can be compensated by adjusting feedback gain of the controller, which can avoid the high-order derivative of the virtual control variable in common backstepping and reduce the complexity of controller and improve adjustability of the controller parameters. Finally, simulation experiments are carried out on WL-II under actuated AUV. The results show that the controller can follow the expected horizontal path precisely, and has theoretical and practical value.

Keywords: backstepping; feedback gain; path following control; underactuated AUV

Regulator praćenja putanje za potpogonjeni AUV zasnovan na interaktivnom pojačanju povratnog koraka

Izvorni znanstveni članak

U svrhu razvoja regulatora praćenja putanje podvodno pogonjenog AUV u horizontalnoj ravnini, predlažemo da se jednadžbe grešaka praćenja postave na osnovu virtualnog cilja te je razvijena nova metoda povratnog koraka (backstepping method) na temelju Lyapunovog teorema stabilnosti i tehnike interaktivnog pojačanja. Nelinearni izrazi u modelu dinamičke greške mogu se kompenzirati podešavajući interaktivno pojačanje regulatora, čime se može izbjeći derivacija visokog reda varijable virtualnog regulatora kod uobičajenog povratnog koraka i smanjiti složenost regulatora te poboljšati podesivost parametara regulatora. Konačno, provedena su simulacijska ispitivanja na WL-II podvodno pogonjenom AUV. Rezultati pokazuju da regulator može precizno pratiti očekivanu horizontalnu putanju te ima teorijsku i praktičnu vrijednost.

Ključne riječi: interaktivno pojačanje; potpogonjen (underactuated) AUV; povratni korak (backstepping); regulator praćenja putanje

\section{Introduction}

With the characteristics of good concealment, costeffectiveness, low energy consumption, etc, the autonomous underwater vehicle (AUV) has potential application prospect in military areas and ocean exploration $[1,2]$. Path following control for the AUV has practical values in mine warfare, ocean mapping, marine environment detection, underwater engineering monitoring and many other fields [3]. The requirement of path following control is that an AUV can be driven by control system along the expected path from any initial position, and reach destination along this trajectory. Due to lack of propellers in the transverse direction and the coupling effects among each degree of freedom, there are difficulties in achieving the precise path following control for the underactuated AUV [4].

Researches focused more on path following control for underactuated surface vessels and AUVs in the horizontal plane $[5 \div 8]$, and combination control of robust and self-adaption were mostly adopted $[9 \div 11]$. Yu Jian Cheng carried out path following experiments in the horizontal plane by direct adaptive control method based on neural network [10]. Tang Xudong put forward a process neuron control model [11]. Repoulias Filoktimon and Lapierre designed a horizontal path following controller based on Lyapunov stability theorem and backstepping method [12]. By introducing an additional controlled variable, the virtual wizard based on SerretFrenet coordinate system has been applied to path tracking control for land robots [13]. Gao Jian proposed a global path tracking control method for the AUV based on the same coordinates to realize the global asymptotic stability of the tracking error [14].
Aiming at path following control for the underactuated AUV in the horizontal plane, backstepping based on feedback gain is proposed to design controller in this paper. Using for reference from that backstepping constructs Lyapunov function through iterative process, we propose to build virtual control variable through state error, which overcomes the disadvantage that common backstepping takes the derivative to virtual control variable continuously during iterative process. By designing the controller parameters, some uncertain symbol, nonlinear terms of Lyapunov energy function are eliminated, which not only simplify controller form compared with common backstepping, but also guarantee the system stability, meanwhile more conducive to project implementation. Finally, simulation experiments in the horizontal plane are carried out by using the proposed method to verify the feasibility.

\section{Problem description}

\subsection{Dynamic model of the under actuated AUV}

Assuming that the AUV has good symmetric structure and good depth control, the influence of vertical trim motion on the coupling action of horizontal motion can be neglected. Point $\mathrm{Q}$ represents the origin in the moving coordinates $\{B\}$. $[x, y, \psi]^{\mathrm{T}}$ represents the position and attitude angle in the fixed coordinates $\{U\} .[x, y, r]^{\mathrm{T}}$ is the state variable. Therefore, dynamic model of the AUV can be written as:

$\left\{\begin{array}{l}F=m_{u} \dot{u}+d_{u} \\ 0=m_{v} \dot{v}+m_{u r} u r+d_{v} \\ T=m_{r} \dot{r}+d_{r}\end{array}\right.$ 


$$
\left\{\begin{array}{l}
m_{u}=m-X_{\dot{u}}, m_{v}=m-Y_{\dot{v}} \\
m_{r}=I_{z}-N_{\dot{r}}, m_{u r}=m-Y_{r} \\
d_{u}=-X_{u u} u^{2}-X_{v v} v^{2} \\
d_{v}=-Y_{v} u v-Y_{v|v|} v|v| \\
d_{r}=-N_{v} u v-N_{v|v|} v|v|-N_{r} u r
\end{array}\right.
$$

where $m$ is the mass of the AUV; $I_{x}$ is the moment of inertia around $Z$ axis; $X_{\dot{u}}, Y_{\dot{v}}, N_{\dot{r}}$ are the variable hydrodynamic coefficients, respectively. Without control inputs in the transverse motion, the number of control inputs is less than state variables, so the controlled system is underactuated [15].

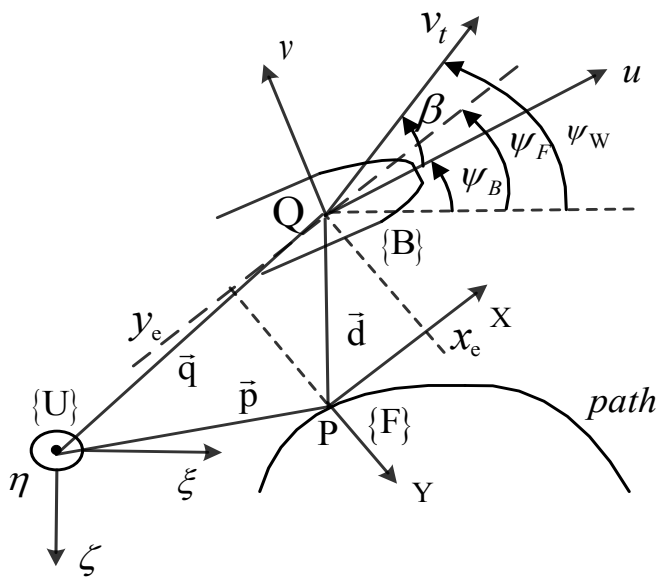

Figure 1 Diagram of horizontal path following for the underactuated AUV

\subsection{Description of path following}

The coordinates of virtual reference point $\mathrm{P}$ on the tracking path $\Omega$ can be described as the function of a scalar parameter $\mu \in R$, so the position of point $\mathrm{P}$ in the fixed coordinates is denoted as:

$$
\mathbf{P}_{\mathbf{p}}(\mu)=\left[x_{p}(\mu), y_{p}(\mu)\right]^{T}
$$

In order to assure the smoothness of tracking curves, $x_{p}(\mu), y_{p}(\mu)$ should be continuous differentiable. So the velocity of the virtual reference point is defined as:

$v_{p}=\left\|v_{p}\right\|=\sqrt{\left(x_{p}^{\prime}\right)^{2}+\left(y_{p}^{\prime}\right)^{2}}$

where $x_{p}^{\prime}=\frac{\mathrm{d} x_{p}}{\mathrm{~d} \mu}, y_{p}^{\prime}=\frac{\mathrm{d} y_{p}}{\mathrm{~d} \mu}$.

The intersection angle $\psi_{F}$ between velocity vector $\boldsymbol{v}_{p}$ and horizontal axis in the fixed coordinates is defined as:

$\psi_{F}=\arctan \left(y_{p}^{\prime} / x_{p}^{\prime}\right)$

The rotating angular velocity $\omega_{F}$ of point $\mathrm{P}$ is defined as:
$\omega_{F}=\dot{\psi}_{F}=c(s) \dot{s}$

where $c(s)=\frac{\mathrm{d} \psi_{F}}{\mathrm{~d} \mu} \frac{\mathrm{d} \mu}{\mathrm{d} s}$ represents the curvature, and parameter $s$ represents directed distance from other fixed points to point $\mathrm{P}$ along the curve. According to the definition of space curve arc length in the differential manifold theory, the relationship between curvilinear scalar parameter $\mu$ and parameter $s$ is obtained as:

$\frac{\mathrm{d} \mu}{\mathrm{d} s}=\frac{1}{\sqrt{\left(x_{p}^{\prime}\right)^{2}+\left(y_{p}^{\prime}\right)^{2}}}$.

\subsection{Kinematic error equations}

As shown in Fig. 1, point $\mathrm{P}$ is the projection of point $\mathrm{Q}$ in the tracking path. Originated by point $\mathrm{P}$, the tangent vector $\boldsymbol{T}$ and normal vector $\boldsymbol{N}$ of the path constitute coordinates $\{S F\}$. The velocity of point $\mathrm{P}$ in the coordinates $\{U\}$ is denoted as $\boldsymbol{v}_{p}$, and $\boldsymbol{R}_{F}$ represents conversion matrix from coordinates $\{U\}$ to $\{S F\}$. According to the vector synthesis formula, the velocity of point $\mathrm{Q}$ in the coordinates $\{U\}$ is written as:

$\boldsymbol{v}_{\mathrm{Q}}=\boldsymbol{v}_{p}+R_{F}^{-}\left(\frac{\mathrm{d} \overline{P Q}}{\mathrm{~d} t}\right)_{F}+R_{F}^{-}\left(\omega_{F} \times \overline{P Q}\right)$,

where

$$
\left\{\begin{array}{l}
\boldsymbol{v}_{Q}=\left[\begin{array}{lll}
\dot{x} & \dot{y} & 0
\end{array}\right]^{\mathrm{T}} \\
\boldsymbol{R}_{F} \boldsymbol{v}_{p}=\left[\begin{array}{lll}
\dot{s} & 0 & 0
\end{array}\right]^{\mathrm{T}} \\
\left(\frac{\mathrm{d} \overline{P Q}}{\mathrm{~d} t}\right)_{F}=\left[\begin{array}{lll}
\dot{x}_{e} & \dot{y}_{e} & 0
\end{array}\right]^{\mathrm{T}} \\
\left(\omega_{F} \times \overline{P Q}\right)=\left[\begin{array}{lll}
-y_{e} c(s) \dot{s} & x_{e} c(s) \dot{s} & 0
\end{array}\right]^{\mathrm{T}} .
\end{array}\right.
$$

The above variables are substituted into Eq. (8), the tracking error equations composed by $x_{e}, y_{e}, \psi$ are obtained as:

$\left\{\begin{array}{l}\dot{x}_{e}=-\dot{s}\left(1-c(s) y_{e}\right)+v_{t} \cos \psi \\ \dot{y}_{e}=-c(s) \dot{s} x_{e}+v_{t} \sin \psi \\ \dot{\psi}=r+\dot{\beta}-c(s) \dot{s}\end{array}\right.$

where $\dot{\psi}=\dot{\psi}_{w}-\dot{\psi}_{F}, \dot{\psi}_{w}=r+\dot{\beta}$.

\section{Design of controller}

The path following controller for the underactuated AUV is designed to realize that according to the tracking error Eq. (10) and dynamic model (1) for a given continuous smooth reference path $\Omega$ and the expected speed $u_{d}>0$, the moving speed $\dot{s}$, axial thrust $F$ and heading torque $\Gamma$ of virtual points along path are obtained 
by backstepping method based on feedback gain to make the tracking error $x_{e}, y_{e}, \psi$, and $u-u_{d}$ asymptotically converge to zero. That is:

$\left\{\begin{array}{l}\lim _{t \rightarrow \infty} x_{e}=0 \\ \lim _{t \rightarrow \infty} y_{e}=0 \\ \lim _{t \rightarrow \infty} \psi=0 \\ \lim _{t \rightarrow \infty}\left(u-u_{d}\right)=0\end{array}\right.$

Speed subsystem, driven by axial thrust $F$, can be used as a separate control subsystem, meanwhile heading and position subsystem are controlled by iterative process.

\subsection{Design of speed subsystem controller}

The longitudinal speed is regulated by a PD controller to make the actual speed $u$ track expected value $u_{d}>0$. If the control input is extracted, the result can be obtained by first one of Eq. (1):

$F_{d}=m_{u}\left(\dot{u}_{d}-\lambda\left(u-u_{d}\right)\right)-d_{u}$

where $d_{u}=-X_{u u} u^{2}-X_{v v} v^{2}, \lambda>0$.

Define $\tilde{u}=u-u_{d}$, so the speed tracking error system satisfies:

$\dot{\tilde{u}}+\lambda \tilde{u}=0$

The result can be obtained that speed tracking error $\tilde{u}$ has exponential convergence, so $\lim _{t \rightarrow \infty}\left(u-u_{d}\right)=0$.

\subsection{Design of position subsystem controller}

Position subsystem controller is designed by backstepping method based on feedback gain technique. Due to that transverse motion has no direct control input and there exists coupling effect between transverse and heading motion, tracking error $y_{e}$ can be regulated by heading torque to realize indirect control. Control error variable and coordinate transformation are designed as:

$$
\left\{\begin{array}{l}
z_{1}=\sqrt{x_{e}^{2}+y_{e}^{2}} \\
z_{2}=\psi-\alpha_{1} \\
z_{3}=r-\alpha_{2}
\end{array}\right.
$$

where $\alpha_{1}, \alpha_{2}$ are equivalent virtual control variables of heading angle and heading angular velocity respectively.

Property $1: \exists 0<\frac{\sin \psi}{\psi} \leq 1, \forall \psi \in(-\pi / 2, \pi / 2)$.

Step 1: Defining Lyapunov function $V_{1}=\frac{1}{2} z_{1}^{2}$, and taking the derivative of two sides of Eq. (10), we can obtain:

$$
\begin{aligned}
\dot{V}_{1} & =z_{1} \dot{z}_{1}=x_{e} \dot{x}_{e}+y_{e} \dot{y}_{e} \\
& =-x_{e} \dot{s}\left(1-c(s) y_{e}\right)+v_{t} x_{e} \cos \psi \\
& -y_{e} c(s) \dot{s} x_{e}+v_{t} y_{e} \sin \psi
\end{aligned}
$$

As can be seen, longitudinal speed $u$ is singly controlled by speed subsystem to make $\lim _{t \rightarrow \infty}\left(u-u_{d}\right)=0$. If the linear velocity of virtual point on the tracking path $\dot{s}$ is adopted as an additional control variable:

$\dot{s}=k_{1} x_{e}+v_{t} \cos \psi$

Substituting Eq. (15) into Eq. (14), we can obtain

$\dot{V}_{1}=-k_{1} x_{e}^{2}+v_{t} y_{e} \sin \psi$

If we adopt common backstepping, we should select $-\arcsin \left(c_{1} y_{e}\right)$ as virtual control variable of the heading angle $\psi$. We have to take the derivative of the virtual control variable to conduct iterative design, which would give rise to complex form of the controller. Aiming at this problem, based on feedback gain compensation, virtual control variable $\alpha_{1}$ in Eq. (13) is adopted in this paper.

$\alpha_{1}=-c_{1} y_{e}, c_{1}>0$

Eq. (16) can be transformed into:

$\dot{V}_{1}=-k_{1} x_{e}^{2}-c_{1} v_{t} y_{e}^{2} \frac{\sin \psi}{\psi}+v_{t} y_{e} \frac{\sin \psi}{\psi}\left(\psi-\alpha_{1}\right)$

In terms of Eq. (12) and Eq. (17), we can obtain

$\dot{z}_{2}=\dot{\psi}-\dot{\alpha}_{1}=r+\dot{\beta}-c(s) \dot{s}+c_{1} \dot{y}_{e}$

Step 2: Define Lyapunov function

$V_{2}=V_{1}+\frac{1}{2} p_{1} z_{2}^{2}, p_{1}>0$

Taking the derivative of two sides of Eq. (10) and Eq. (19), we can obtain:

$$
\begin{aligned}
& \dot{V}_{2}=-k_{1} x_{e}^{2}-c_{1} v_{t} y_{e}^{2} \frac{\sin \psi}{\psi}+v_{t} y_{e} \frac{\sin \psi}{\psi} z_{2}+p_{1} z_{2} \dot{z}_{2} \\
& =-k_{1} x_{e}^{2}-c_{1} v_{t} y_{e}^{2} \frac{\sin \psi}{\psi}+p_{1} z_{2}\left[\dot{z}_{2}+\frac{v_{t} y_{e}}{p_{1}} \frac{\sin \psi}{\psi}\right] \\
& =-k_{1} x_{e}^{2}-c_{1} v_{t} y_{e}^{2} \frac{\sin \psi}{\psi} \\
& +p_{1} z_{2}\left[\begin{array}{l}
r+\dot{\beta}-c(s) \dot{s}\left(1+c_{1} x_{e}\right)+ \\
c_{1} z_{2} v_{t} \frac{\sin \psi}{\psi}+\left(\frac{1}{p_{1}}-c_{1}^{2}\right) v_{t} y_{e} \frac{\sin \psi}{\psi}
\end{array}\right]
\end{aligned}
$$


We may as well define $p_{1}=1 / c_{1}^{2}$ to eliminate the nonlinear term in Eq. (21). Through the selection compensation of controller gain parameters, the final form of controller can be simplified, which is convenient for the actual system hardware design, and makes backstepping more easily engineering realized. This is the significance of backstepping method based on feedback gain.

Define the virtual control variable $\alpha_{2}$ in Eq. (13) as:

$\alpha_{2}=-c_{2} z_{2}-\dot{\beta}+c(s) \dot{s}\left(1+c_{1} x_{e}\right)$

Eq. (21) is simplified as:

$$
\begin{aligned}
\dot{V}_{2}= & -k_{1} x_{e}^{2}-c_{1} v_{t} y_{e}^{2} \frac{\sin \psi}{\psi} \\
& -c_{2} p_{1} z_{2}^{2}\left(1-\frac{c_{1} v_{t}}{c_{2}} \frac{\sin \psi}{\psi}\right)+p_{1} z_{2}\left(r-\alpha_{2}\right)
\end{aligned}
$$

In terms of Eq. (13) and Eq. (22), Eq. (23) can be transformed into:

$$
\dot{V}_{2}=-k_{1} x_{e}^{2}-c_{1} v_{t} y_{e}^{2} \frac{\sin \psi}{\psi}-c_{1} p_{1} z_{2}^{2}\left(1-\frac{c_{1} v_{t}}{c_{2}} \frac{\sin \psi}{\psi}\right) \leq 0
$$

$c_{2}>c_{1} v_{t}>0$ is satisfied by selecting proper controller parameter $c_{2}$. From property 1, we deduce $1-\frac{c_{1} v_{t}}{c_{2}} \frac{\sin \psi}{\psi}>0$, so Eq. (24) can be assured.

In terms of Eq. (13) and Eq. (22), we can obtain:

$$
\begin{aligned}
\dot{z}_{3}= & \dot{r}-\dot{\alpha}_{2} \\
= & \dot{r}+\ddot{\beta}-\left(\frac{\partial c(s)}{\partial s} \dot{s}^{2}+c(s) \ddot{s}\right)\left(1+c_{1} x_{e}\right) \\
& -c_{1} c(s) \dot{s} \dot{x}_{e}+c_{2}\left(\dot{\psi}+c_{1} \dot{y}_{e}\right)
\end{aligned}
$$

where

$$
\begin{aligned}
\ddot{\beta} & =\frac{1}{v_{t}^{2}}(\ddot{v} u-\ddot{u} v)-2 \frac{\dot{v_{t}}}{v_{t}} \dot{\beta} \\
& =-\frac{m_{u r}}{m_{v}} \cos ^{2} \beta \dot{r}-\frac{u}{v_{t}^{2}}\left(\frac{m_{u r}}{m_{v}} \dot{u} r+\frac{\dot{d}_{v}}{m_{v}}\right)-\frac{\ddot{u} v}{v_{t}^{2}}-2 \frac{\dot{v}_{t}}{v_{t}} \dot{\beta} \\
& =-\frac{m_{u r}}{m_{v}} \cos ^{2} \beta \dot{r}-\frac{u}{v_{t}^{2}}\left(\frac{m_{u r}}{m_{v}} \dot{u} r+\frac{\dot{d}_{v}}{m_{v}}\right)-\frac{\ddot{u} v}{v_{t}^{2}}-2 \frac{\dot{v}_{t}}{v_{t}} \dot{\beta}
\end{aligned}
$$

Step 3: Define Lyapunov function $V_{3}$ :

$$
V_{3}=V_{2}+\frac{1}{2} p_{2} z_{3}^{2}, p_{2}>0
$$

In terms of Eq. (23) and Eq. (25), we can obtain:

$$
\begin{aligned}
\dot{V}_{3} & =-k_{1} x_{e}^{2}-c_{1} v_{t} y_{e}^{2} \frac{\sin \psi}{\psi}-c_{2} p_{1} z_{2}^{2}\left(1-\frac{c_{1} v_{t}}{c_{2}} \frac{\sin \psi}{\psi}\right) \\
& +p_{1} z_{2} z_{3}+p_{2} z_{3} \dot{z}_{3} \\
& =-k_{1} x_{e}^{2}-c_{1} v_{t} y_{e}^{2} \frac{\sin \psi}{\psi}-c_{2} p_{1} z_{2}^{2}\left(1-\frac{c_{1} v_{t}}{c_{2}} \frac{\sin \psi}{\psi}\right) \\
& +p_{2} z_{3}\left(\frac{p_{1} z_{2}}{p_{2}}+\dot{z}_{3}\right) \\
& =-k_{1} x_{e}^{2}-c_{1} v_{t} y_{e}^{2} \frac{\sin \psi}{\psi}-c_{2} p_{1} z_{2}^{2}\left(1-\frac{c_{1} v_{t}}{c_{2}} \frac{\sin \psi}{\psi}\right) \\
& +p_{2} z_{3}\left(\dot{r}\left(1-\frac{m_{u r}}{m_{v}} \cos ^{2} \beta\right)+f_{\alpha}+\frac{p_{1} z_{2}}{p_{2}}\right)
\end{aligned}
$$

where

$$
\begin{aligned}
f_{\alpha}= & -\frac{u}{v_{t}^{2}}\left(\frac{m_{u r}}{m_{v}} \dot{u} r+\frac{\dot{d}_{v}}{m_{v}}\right)-\frac{\ddot{u} v}{v_{t}^{2}}-2 \frac{\dot{v}_{t}}{v_{t}} \dot{\beta}- \\
& \left(\frac{\partial c(s)}{\partial s} \dot{s}^{2}+c(s) \ddot{s}\right)\left(1+c_{1} x_{e}\right)- \\
& c_{1} c(s) \dot{s} \dot{x}_{e}+c_{2}\left(\dot{\psi}+c_{1}\left(-c(s) \dot{s} x_{e}+v_{t} \sin \psi\right)\right)
\end{aligned}
$$

So the equivalent control input is obtained as:

$$
T=\frac{m_{r}}{1-\frac{m_{u r}}{m_{v}} \cos ^{2} \beta}\left(-c_{3} z_{3}-f_{\alpha}-\frac{p_{1}}{p_{2}} z_{3}\right)+d_{r}, c_{3}>0
$$

where

$\left\{\begin{array}{l}z_{2}=\psi+c_{1} y_{e} \\ z_{3}=r-\alpha_{2}=r-c(s) \dot{s}\left(1+c_{1} x_{e}\right)+\dot{\beta}+c_{2}\left(\psi+c_{1} y_{e}\right)\end{array}\right.$

Substituting equivalent control input of Eq. (29) into Eq. (27), we can obtain:

$\dot{V}_{3}=-k_{1} x_{e}^{2}-c_{1} y_{e}^{2} v_{t} \frac{\sin \psi}{\psi}-p_{1} c_{2} z_{2}^{2}\left(1-\frac{c_{1} v_{t}}{c_{2}} \frac{\sin \psi}{\psi}\right)-p_{2} c_{3} z_{3}^{2}$

If the selected controller parameters meet the conditions: $k_{1}>0, c_{1}>0, c_{2}>c_{1} v_{t}, c_{3}>0, p_{1}=1 / c_{1}^{2}$, $p_{2}>0$, then $\dot{V}_{3} \leq 0$. If and only if $\left(x_{e}, y_{e}, z_{2}, z_{3}\right)=(0,0,0,0), \dot{V}_{3}=0$. Based on Lasalle invariance principle in [16], the system is asymptotically stable by selecting reasonable controller parameters $c_{1}, c_{2}, c_{3}, p_{1}, p_{2}$ and $k_{1}$.

\section{Simulation}

We select WL-II underactuated AUV to carry out simulation experiments, which is a mini underactuated AUV made in Harbin Engineering University, China [17]. The nominal model parameters of the AUV are in Tab. 1. 


Table 1 Model parameters of AUV
\begin{tabular}{|c|c|c|c|}
\hline Parameters & Value & Parameters & Value \\
\hline$m$ & $45 \mathrm{~kg}$ & $Y_{v}$ & $-50,2 \mathrm{~kg} / \mathrm{s}$ \\
\hline$I_{z}$ & $8,1 \mathrm{~kg} \cdot \mathrm{m}^{2}$ & $Y_{v|v|}$ & $-182,3 \mathrm{~kg} / \mathrm{m}$ \\
\hline$L$ & $1,46 \mathrm{~m}$ & $N_{\dot{r}}$ & $-5,5 \mathrm{~kg} \cdot \mathrm{m}^{2}$ \\
\hline$X_{\dot{u}}$ & $-2,5 \mathrm{~kg}$ & $N_{r}$ & $\begin{array}{c}-27,2 \\
\mathrm{~kg} \cdot \mathrm{m}^{2} /(\mathrm{s} \cdot \mathrm{rad})\end{array}$ \\
\hline$X_{u}$ & $-13,5 \mathrm{~kg} / \mathrm{s}$ & $N_{r|r|}$ & $\begin{array}{c}-4,9 \\
\mathrm{~kg} \cdot \mathrm{m}^{2} / \mathrm{rad}^{2}\end{array}$ \\
\hline$X_{u|u|}$ & $-6,4 \mathrm{~kg} / \mathrm{m}$ & $X_{\max }$ & $30 \mathrm{~N}$ \\
\hline$Y_{\dot{v}}$ & $-49,1 \mathrm{~kg}$ & $N_{\max }$ & $15 \mathrm{~N} \cdot \mathrm{m}$ \\
\hline
\end{tabular}

$\dot{\varepsilon}+T_{E} \varepsilon=\omega$

where $\omega$ represents white Gaussian noise, and time constant $T_{E}>0$.

7.

The simulation results are shown in Fig. 3 to Fig.

The expected parameterized tracking path is written as $(\mathrm{m})$ :

$$
\left\{\begin{array}{l}
x_{p}(\mu)=\mu \\
y_{p}(\mu)=A \cos (\omega \mu)
\end{array}\right.
$$

where $A=10, \omega=0,02 \pi$.

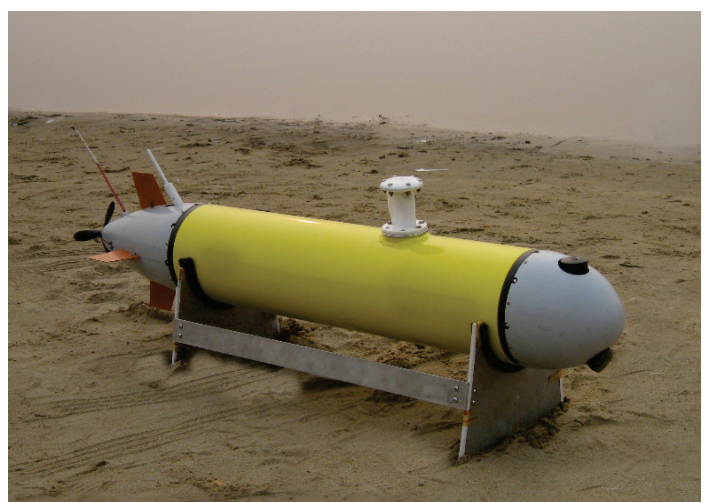

Figure 2 WL-II underactuated AUV

The initial conditions of the AUV in the simulation 1 and 2 are:

$$
\left\{\begin{array}{l}
{[u, v, r, x, y, \psi]^{T}=[0.1,0,0,10,30,-\pi / 4]^{T}} \\
{[u, v, r, x, y, \psi]^{T}=[0.1,0,0,10,-15, \pi / 4]^{T}}
\end{array}\right.
$$

The initial condition of virtual targets on the reference path is:

$\left[u_{p}, x_{d}, y_{d}, \psi_{d}\right]=[0,15,0,0]$

Expected speed of the AUV $u_{d}=1 \mathrm{~m} / \mathrm{s}$. Given that the amplitudes of state error variables $z_{1}, z_{2}$ and $z_{3}$ are $10 \mathrm{~m}, \pi \mathrm{rad}$, and $0,1 \mathrm{rad} / \mathrm{s}$ respectively, the control parameters $p_{1}, p_{2}$ can perform normalization processing to different state variables to make these three state variables play an equal role in energy function $V_{3}$. Select parameters as $p_{1}=3, p_{2}=10^{2}$, the linear velocity gain parameter as $k_{1}=0,5$, and other controller parameters as $c_{1}=1 / 9, c_{2}=0,5 c_{3}=1$. To verify the feasibility of the controller at different initial conditions and disturbances, an additional disturbance signal $\varepsilon$ is set as:

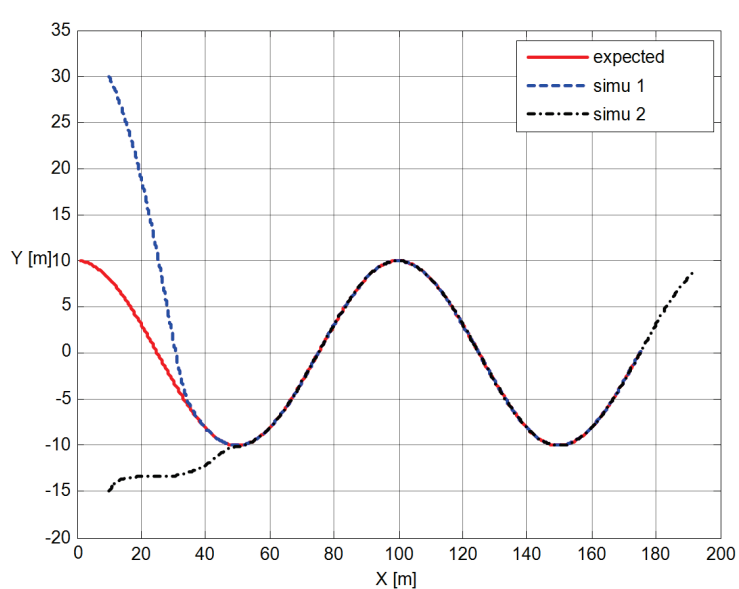

Figure 3 Curves of path following control
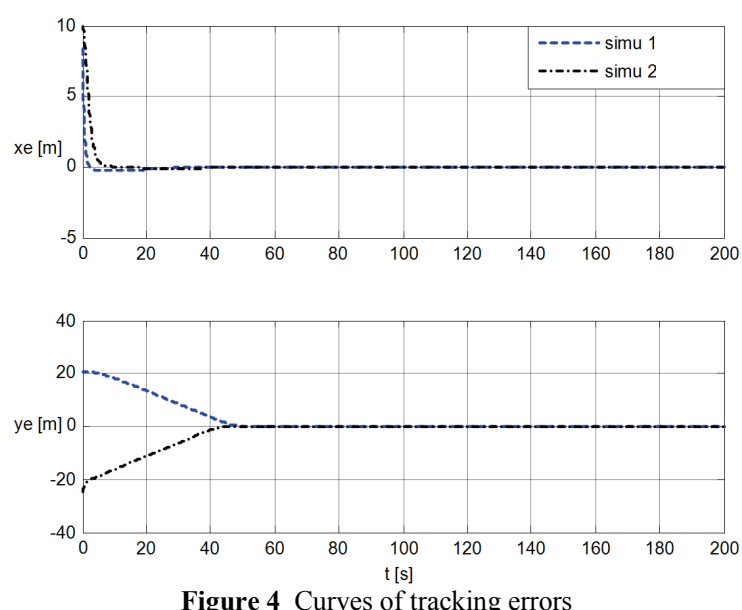

Fig. 3 shows that the designed controller in this paper can make the underactuated AUV WL-II follow the expected path smoothly in different initial conditions and the existence of disturbance, which verify the feasibility. Fig. 4 shows that the tracking errors converge to zero quickly, which verifies the high precision of the designed controller.
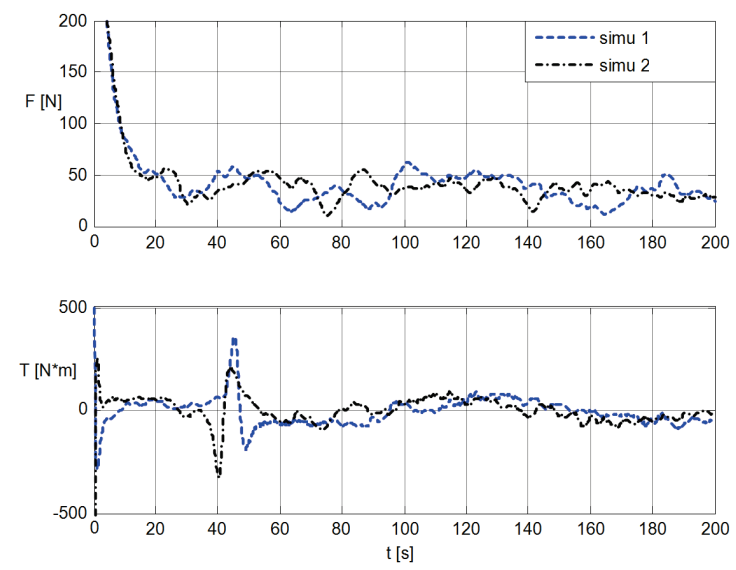

Figure 5 Curves of control inputs 
Fig. 5 are curves of control inputs, from which we can see that the control inputs can effectively suppress interference and guarantee the tracking performance of the controller. Fig. 6 are response curves of system state variable. Fig. 7 are moving speed response curves of virtual guide point on expected path, and the speed of virtual guide point converges to $1 \mathrm{~m} / \mathrm{s}$.

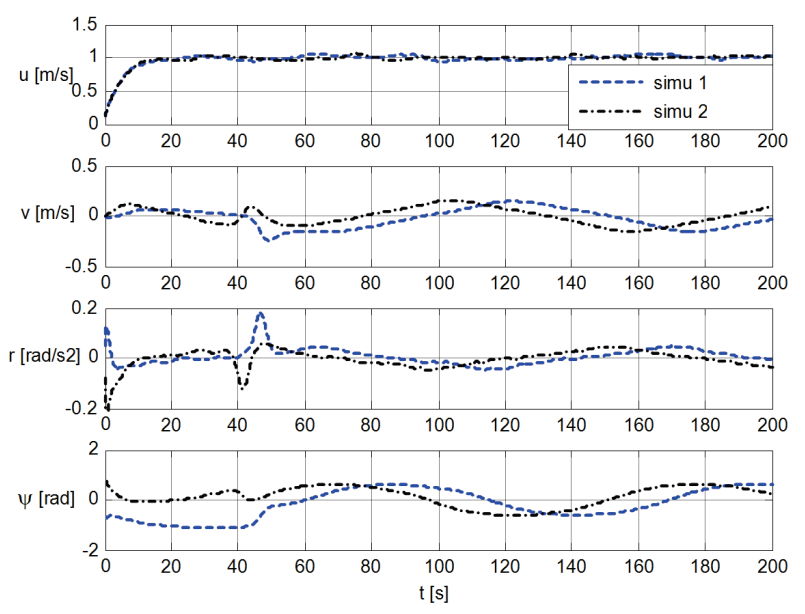

Figure 6 Response curves of system state variable

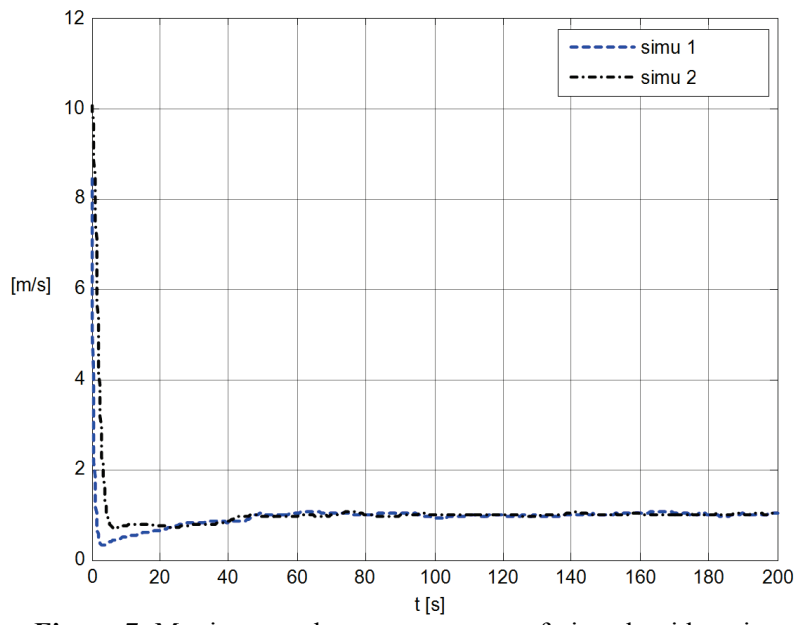

Figure 7 Moving speed response curves of virtual guide point

\section{Conclusions}

Aiming at path following control for the underactuated AUV in the horizontal plane, combined with Serret-Frenet coordinate system, a backstepping controller is designed based on feedback gain technique in this paper, which avoids the high-order derivative of the virtual control variable in the common iteration process. The designed controller depends on state errors and tracking path parameters, which can reduce the complexity of controller and improve adjustability of the controller parameters. The results of simulation experiments show that the controller can follow the expected horizontal path precisely, and has theoretical and practical value.

\section{Acknowledgement}

This work is supported by the National Natural Science Foundation of China (Grant No. 51209025, 51379026, 51579022) and Fundamental Research
Funds for the Central Universities of China (Grant No. 3132015088, 3132014067, 3132014318).

\section{References}

[1] Xu, Y. R.; Pang, Y. J.; Gan, Y.; Sun, Y. S. AUV-state-ofthe-art and prospect. // CAAI Transactions on Intelligent Systems. 1, 1(2006), pp. 9-16.

[2] Xu, Y. R.; Xiao, K. Technology development of autonomous ocean vehicle. // Journal of Automation. 33, 5(2007), pp. 518-521.

[3] Zhang, L. J.; Jia, H. M.; Bian, X. Q.; Yan, Z. P.; Cheng, X. Q. Three-dimensional path tracking control for an autonomous underwater vehicle based on L-two disturbance attenuation method. // Control Theory and Applications. 28, 5(2011), pp. 645-651.

[4] Jia, H. M.; Cheng, X. Q.; Zhang, L. J.; Bian, X. Q.; Yan, Z. P. Three-dimensional path tracking control for an underactuated AUV based on discrete-time sliding mode prediction. // Control Theory and Applications. 26, 10(2011), pp. 1452-1458

[5] Lapierre, L.; Jouvencel, B. Robust Nonlinear PathFollowing Control of an AUV. // IEEE Journal of Oceanic Engineering. $\quad 33, \quad 2(2008), \quad$ pp. 89-102. DOl: 10.1109/JOE.2008.923554

[6] Yu, J. C.; Li, Q.; Zhang, A. Q.; Wang, X. H. Neural network adaptive control for underwater vehicles. // Control Theory and Applications. 25, 1(2008), pp. 9-13.

[7] Tang, X. D.; Pang, Y. J.; Li, Y., Zhang, H. Chaotic process neuron control for AUVs. // Control and Decision. 25, 2(2010), pp. 213-217.

[8] Liao, Y. L.; Wan, L.; Zhuang, J. Y. Backstepping Dynamical Sliding Mode Control Method for the Path Following of the Underactuated Surface Vessel. // Procedia Engineering. 25, 1(2011), pp. 256-263. DOI: 10.1016/j.proeng.2011.08.051

[9] Do, K. D. Practical control of underactuated ships. // Ocean Engineering. 37, 13(2010), pp. 1111-1119. DOI: 10.1016/j.oceaneng.2010.04.007

[10] Zhou, H. Y.; Liu, K. Z.; Feng, X. S. Dynamic feedback control based on ANN compensation controller for AUV motions. // Electric Machines and Control. 23, 3(2011), pp. 341-346.

[11] Zhen, L.; Sun, J.; Soryeok, Oh. Design, analysis and experimental validation of a robust nonlinear path following controller for marine surface vessels. // Automatica. 45, 7(2009), pp. 1649-1658. DOI: 10.1016/j.automatica.2009.03.010

[12] Repoulias, F.; Papadopoulos, E. Planar trajectory planning and tracking control design for underactuated AUVs. // Ocean Engineering. 34, 7(2007), pp. 1650-1667. DOI: 10.1016/j.oceaneng.2006.11.007

[13] Casalino, G.; Aicardi, M.; Bicchi, A.; Balestrino, A. Closed loop steering and path-following for unicycle-like vehicles: a simple Lyapunov function based approach. // IEEE Robotics and Automation Magazine. 2, 1(1995), pp. 27-35. DOI: 10.1109/100.388294

[14] Gao, J.; Yan, W. S.; Zhao, N. N.; Xu, D. M. Global Path Following Control for Unmanned Underwater Vehicles. // Proceedings of the $29^{\text {th }}$ Chinese Control Conference / China, 2010, pp. 3188-3192.

[15] Guo, C.; Wang, Y.; Sun, F. C.; Shen, Z. P. Survey for motion control of underwater surface vessels. // Control and Decision. 24, 3(2009), pp. 321-329.

[16] Khalil, Hanssan. Nonlinear Systems. USA: Prentice -Hall, 2002.

[17] Wang, F.; Wan, L.; Li, Y.; Su, Y. M.; Xu, Y. R. A Survey on Development of Motion Control for Underactuated AUV. // Shipbuilding of China. 51, 2(2010), pp. 227-241. 


\section{Authors' addresses}

Xiao Liang

Dalian Maritime University,

College of Traffic Equipment and Ocean Engineering,

1 Linghai Road, 116024 Dalian, China

E-mail: liangxiao19801012@126.com

\section{Yuan You}

Dalian Maritime University,

College of Traffic Equipment and Ocean Engineering,

1 Linghai Road, 116024 Dalian, China

E-mail: yuanyou1991@126.com

\section{Linfang $S u$}

Dalian Maritime University,

College of Traffic Equipment and Ocean Engineering,

1 Linghai Road, 116024 Dalian, China

E-mail: linfangsu168@hotmail.com

Wei Li

Dalian Maritime University,

College of Environmental Science and Engineering,

1 Linghai Road, 116024 Dalian, China

E-mail: weiwei99231@126.com

Jundong Zhang (corresponding author)

Dalian Maritime University,

College of Marine Engineering,

Lingshui Rd, Ganjingzi, 116024 Dalian,

Liaoning, China

E-mail: zhangjundong@dlmu.edu.cn 